\title{
SESAME: Exploring small businesses' behaviour to enhance resilience to flooding
}

\author{
Graham Coates ${ }^{1, a}$, Nigel Wright ${ }^{2}$, Martina McGuinness ${ }^{3}$, Dabo Guan $^{4}$, Tim Harries $^{5}$ and Lindsey McEwen ${ }^{6}$ \\ ${ }^{1}$ School of Engineering and Computing Sciences, Durham University, Durham, United Kingdom \\ ${ }^{2}$ School of Engineering and Sustainable Development, De Montfort University, Leicester, United Kingdom \\ ${ }^{3}$ Management School, University of Sheffield, Sheffield, United Kingdom \\ ${ }^{4}$ School of International Development, University of East Anglia, Norwich, United Kingdom \\ ${ }^{5}$ Business School, Kingston University, Kingston, United Kingdom \\ ${ }^{6}$ Department of Geography and Environmental Management, University of the West of England, Bristol, United Kingdom
}

\begin{abstract}
In the United Kingdom, small and medium sized enterprises (SMEs) account for approximately 99.9\% of businesses, $60 \%$ of the working population and $47 \%$ annual turnover. However, despite the important contribution that SMEs make to the economy, this size of business remains under-researched with a significant gap in understanding how the disruption caused by flooding impacts on SMEs from the time at which a flood event occurs through to the 'return' to normal operations. Business continuity management is a recognised approach for enhancing organisational resilience to major disruptions (ISO 22301, 2012). However, this strategic approach to building such resilience in SMEs is under-explored in the literature with a limited range of empirical data to draw on. This paper presents an overview of an inter-disciplinary research project funded by the UK's Engineering and Physical Science Research Council, called SESAME, which examines SMEs' operational response and preparedness to flooding. Furthermore, SESAME consists of four stands of research which bring together a number of disciplines including agent based modelling and simulation, flood modelling, business continuity management, economic modelling and behavioural science. This paper provides an overview of the different research stands within the SESAME project aimed at enhancing SMEs' resilience to flooding.
\end{abstract}

\section{Introduction}

Many parts of the world continue to suffer from severe flooding which causes significant damage and disruption to individuals, households, communities and businesses. In the United Kingdom (UK), recent years have seen businesses suffer significant losses in terms of interruption to operations and damage to property. Indeed, the Environment Agency (EA) estimates the financial cost of the 2007 and 2012 floods to UK businesses at approximately $£ 740$ million and $£ 600$ million respectively [1]. Such losses are most acutely felt by Small and Medium Enterprises (SMEs) which, in the UK, account for $99.9 \%$ of private sector businesses, $60 \%$ of employment and $47 \%$ of annual turnover [2]. Importantly, in comparison to large businesses, SMEs have different vulnerabilities to flooding. For example, SMEs have limited resources and capabilities which they can bring to bear in preparing and responding to flood events than those of large businesses [3-4].

The UK's Engineering and Physical Sciences Research Council has funded three major projects, including the SESAME project [5], focussing on the research of innovative solutions to flood risk management. This paper provides an overview of the
SESAME project which is aimed at influencing the behaviours of businesses faced with flooding and flood risk. More specifically, this paper presents progress on the four inter-related strands of research being conducted as part of the SESAME project: (i) developing and using agent based modelling, coupled with flood modelling, to simulate SME behaviours during and in the short-term aftermath of a flood event; (ii) understanding the behaviours of SMEs in relation to flooding, and why they do not tend to plan for floods and how these businesses cope when these events occur; (iii) assessing the financial impacts of SME flooding on the wider economy; (iv) understanding what stands in the way of long-term resilience-building in SMEs.

\section{Background}

The increased severity and frequency of major flood events in the UK along with their significant impact, including the aforementioned economic losses to businesses, have led to flood risk management becoming increasingly high on the political agenda. Consequently, means of reducing the economic impact of interruptions attributable to flooding at the business level, and more widely, are receiving growing attention. Effective

\footnotetext{
${ }^{\text {a }}$ Corresponding author: graham.coates@durham.ac.uk
} 
business continuity management (BCM) is one means of reducing the effect of flooding on business operations and enabling a more rapid return to normality. Indeed, BCM is viewed as an important tool for business survival in the face of a range of disruptive events [6-7], including flooding, and a key part of any successful flood response [8]. The International Organization for Standardization's ISO 22301, which is related to BCM, is described as the requirements which will help organisations to be better prepared and handle disruptions of any type [9]. However, despite the existence of such standards, in the UK organisational engagement with business continuity remains low with less take-up by SMEs relative to larger businesses and public sector bodies [10-11].

\section{SESAME}

The SESAME project aims to investigate how SMEs may improve their preparedness and response to flooding and thus enhance their resilience to such disruptive events. To achieve this aim, four integrated and interdisciplinary strands of research are being pursued, as indicated in Figure 1.

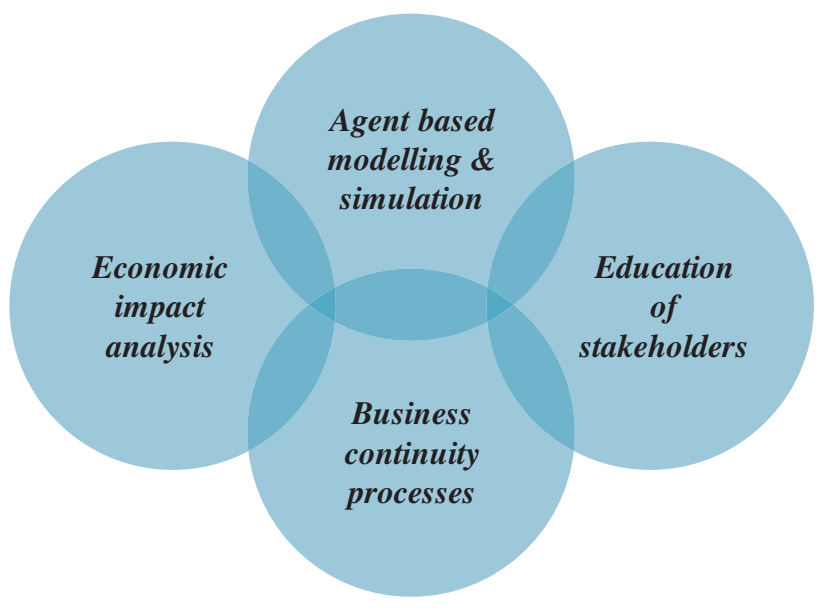

Figure 1. Overview of the SESAME project's research strands.

Firstly, there is a need to achieve a better understanding of business continuity processes and how businesses behave and interact with each other, and other organisations, in the immediate aftermath of flood events. Secondly, there is a need to establish how agent based modelling and simulation, coupled with flood modelling, can be used to enable what-if scenarios to be played-out leading to the identification of those actions and behaviours of SMEs that may lessen the impact of a flood event and reduce the time taken to return to normal operations. Thirdly, there is a need to assess the impacts of flooding on economic systems both within and beyond the immediately affected area. Fourthly, there is a need to develop innovative approaches to the promotion of organisational behaviour change and adaptive organisational learning throughout the flood cycle. In pursuing each of these four strands, the research exploits synergies between the academic fields of business continuity management, agent based modelling and simulation, flood modelling, economic modelling and the social/behavioural sciences. To follow is an indication of the work undertaken in each of the four strands of research indicated in Figure 1, namely:

- agent-based modelling and simulation;

- business continuity processes;

- economic impact analysis;

- education of stakeholders.

\subsection{Agent-based modelling and simulation}

This research strand is aimed at developing an agent based modelling and simulation (ABMS) approach, coupled with flood modelling, to enable the investigation of small businesses' behaviour in the face of flood events. Achieving this aim involves developing: (i) the agentbased model's (ABM's) virtual geographic environment, which is able to combine Ordnance Survey information with flood model output, to identify the businesses affected by the flood event considered; (ii) agents to model businesses, and associated organisations, in terms of their attributes, behaviours, actions and interactions in response to flooding; (iii) an agent interaction network to enable simulations to be performed to evaluate the effectiveness of different combinations of actions and behaviours. Figure 2 provides an overview of the ABMS approach.

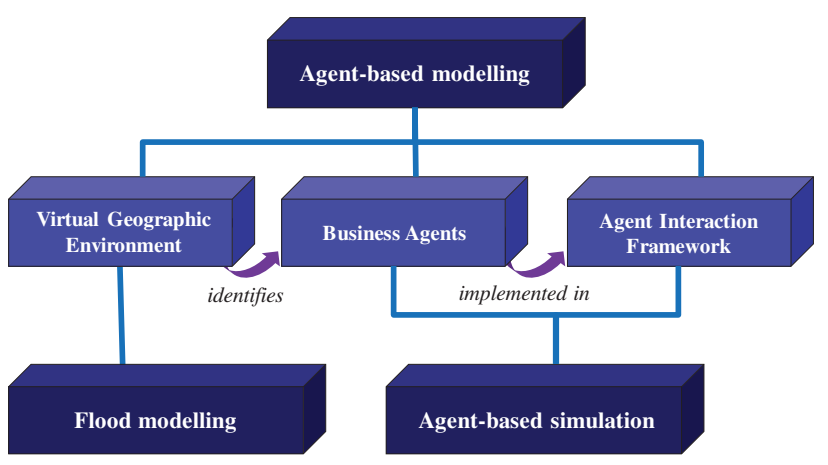

Figure 2. Agent-based modelling and simulation.

\subsubsection{Classifying businesses and organisations}

The ABM's virtual geographic environment (VGE) has been developed to identify and classify the businesses and other organisations within the case study areas considered, and based on inundation data for the particular flood scenario modelled, which of these businesses and organisations are flooded and to what extent in terms of depth of water and length of time. The ABM's VGE software classifies businesses and organisations according to the National Land Use Database (NLUD) code, which consists of 41 groups, within the Address Layer of Ordnance Survey's MasterMap ${ }^{\circledR}$ [12]. For the two case study areas considered in this strand of research, namely Sheffield's Lower Don Valley and Tewkesbury, an analysis has been performed using the VGE software to identify the types of businesses in these areas as shown in Figure 3. 


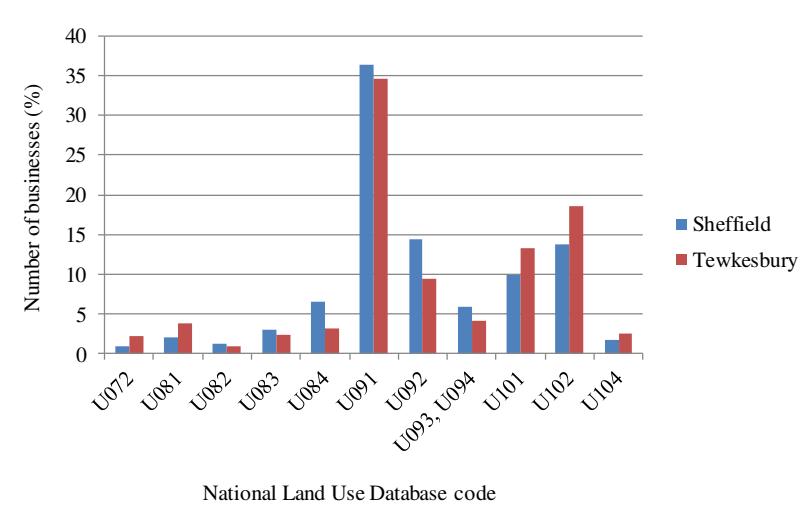

Figure 3. Business/organisation by type ( $>1 \%$ share).

Within the Sheffield and Tewkesbury case study areas, the VGE identified 5570 and 692 business and organisations respectively. Further, as shown in Figure 3, retail (U091 for shops, U092 for financial and professional services) along with industry and business (U101 for manufacturing, U102 for offices) are shown to dominate in both case study areas considered. Furthermore, the percentage of businesses in the NLUD groupings is shown to be similar in both case study areas.

This analysis represents an important part of this research strand as it provides input for the ABM in terms of identifying the SMEs in the geographical area considered, along with a classification of the type and the precise location of each, and based on inundation data for the particular flood scenario modelled, which of these businesses experiences flooding and to what extent in terms of depth of water and length of time.

\subsubsection{Flood modelling}

In order to analyse the operation and performance of SMEs during and in the short-term aftermath of flooding, hydrodynamic modelling of flood events in both Sheffield's Lower Don Valley and Tewkesbury has provided estimated water depths at regular time intervals during the simulated event. These estimates, after an analysis via the VGE software, are used as input for agent-based simulations. Flood simulations have been performed of (1) a one in 1000 year flood event of the River Don at the Lower Don Valley region of Sheffield, and (2) the July 2007 flood event in Tewkesbury. In this paper, for this research strand, a focus is placed on the flooding in Tewkesbury, which was severely affected when the combined pluvial and fluvial floods inundated the city. The heavy rainfall overloaded drainage systems due to the influx of surface water, and very high water levels in two main rivers, namely the Severn and Avon, led to flooding in most areas of Tewkesbury which lasted approximately two weeks. Simulation results of the July 2007 event, based on the 2D LISFLOOD-FP model of Tewkesbury at $10 \mathrm{~m}$ resolution developed by Bristol University, are shown in Figure 4. Furthermore, as shown in Figure 4, Tewkesbury essentially became an island, including the high street area.
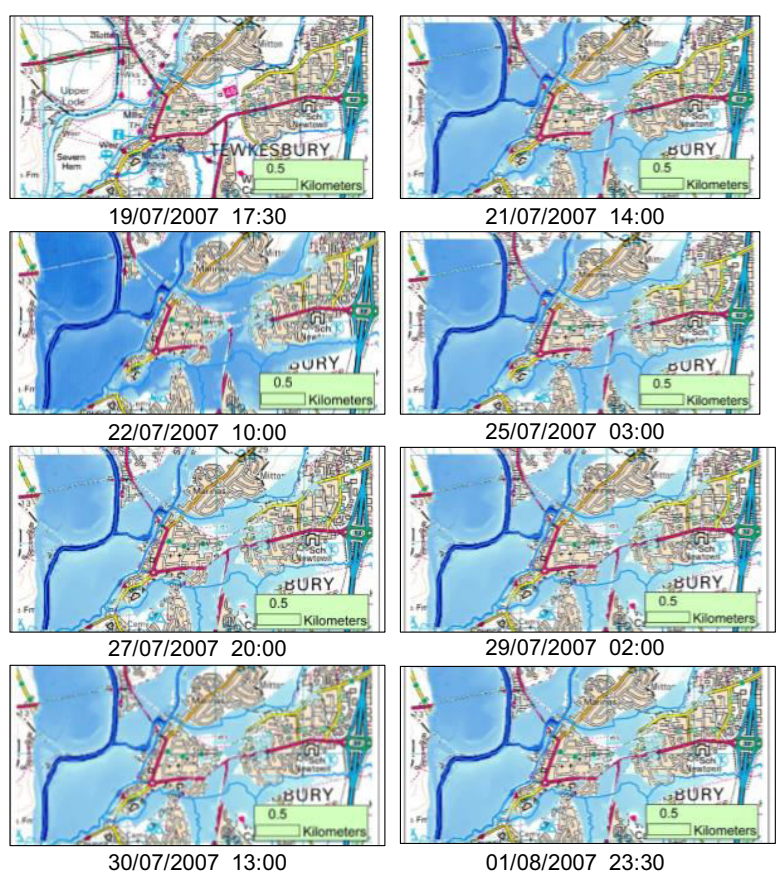

Figure 4. 2007 flood simulation of Tewkesbury.

\subsubsection{Using the VGE with inundation data from flood modelling}

For the Tewkesbury case study, the inundation data associated with the maps shown in Figure 4 provide the input for the ABM's VGE, which, in turn, provides input for agent-based simulations. As an example, based on inundation data for Tewkesbury, VGE output is shown in Figure 5 which corresponds with 10.00 a.m. on 22 July 2007. In agent-based simulations, the provision of dynamic inundation data allows agents representing flooded businesses to act accordingly in light of the depth of water at their respective premises at different times throughout the flood event modelled.

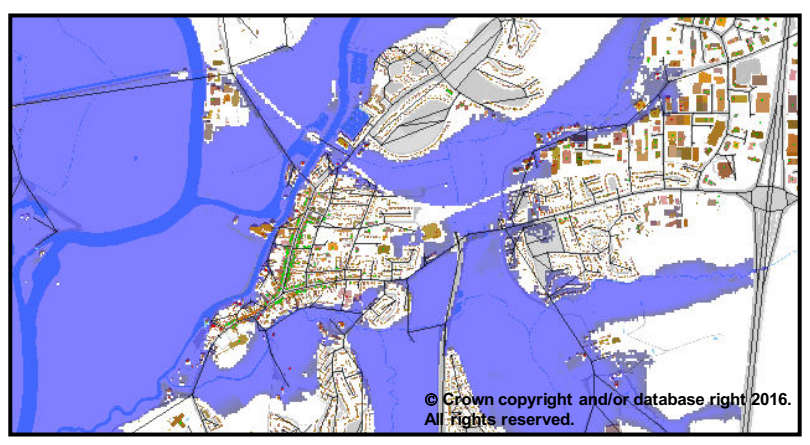

Figure 5: VGE output for Tewkesbury flood, 22/07/07 (10am).

In preparation for carrying out agent-based simulations, in addition to the VGE analysis of the inundation data for Tewkesbury, an analysis has been performed for a one in 1000 year flood event of the River Don at the Lower Don Valley region of Sheffield. 


\subsubsection{Attributes and behaviours of businesses modelled as agents}

Business agents' attributes and behaviours have been derived from a number of sources: (a) information extracted from transcripts of semi-structured interviews with SMEs at risk of flooding and/or that have experienced flooding, which have been conducted by colleagues from other research strands; (b) discussions with the aforementioned colleagues to ensure the attributes and behaviours, and the relations between behaviours, being used to model SMEs were appropriate and relevant; (c) Environment Agency literature providing advice for businesses preparing for flooding; (d) literature detailing business continuity management (BCM) systems' requirements (ISO223301). In this research, SME behaviours extracted from interview transcripts are referred to as 'typical' or 'existing' behaviours whereas those found in EA and BCM literature are referred to as 'enhanced' or 'potential' behaviours. This distinction is made as it provides the basis for a comparative analysis in the modelling and simulation environment in terms of what SMEs did when flooded in the past and what they may do in the future.

\subsubsection{Agent interaction network}

Simulations of the behaviours of business agents during and in the short term aftermath of a flood event has required the development of other agents to model organisations such as suppliers, customers and service companies. In addition, relationships between SMEs and these organisations have been modelled since some of them will influence the response and recovery of an SME when a flood event occurs. For, example, the existence of a pre-agreed priority relationship between an SME and a service company may lead to preferential treatment thus expediting recovery and resumption of normal operations. Similarly, the existence of a pre-existing mutual aid agreement between SMEs may enable the flood affected SME to resume some degree of production operations, in the case of engineering/manufacturing SMEs, thus enabling customer demands to be met to a greater degree than if such an arrangement was not in place.

\subsubsection{Preliminary simulations and design of experiments}

As part of the process of developing the agent-based model software for SMEs' existing and potential behaviours, preliminary simulations have been conducted in order to assess the functionality of the code. For illustrative purposes, some sample output from a preliminary simulation is shown in Figure 6. In terms of future simulations, experiments are currently being designed which will enable assessments to be made of the effect of different combinations of behaviours in terms of the performance of the small businesses modelled.

Simulating small businesses during and in the shortterm aftermath of flood events enables what-if scenarios/experiments to be performed in order to investigate the effect of different behaviours in terms of operational response and business continuity. As alluded to earlier, for illustrative purposes, output from a preliminary simulation for a manufacturing/engineering SME with a mutual aid agreement in place is shown in Figure 6. In this particular 'development' simulation, the engineering/manufacturing SME operates normally until an EA warning is received (vertical green arrow on the horizontal 'time' axis) at which point employees undertake activities such as lifting up equipment and sealing doors. At this point in time, production capacity level, which is a function of number of employees, machines and amount of raw materials available for production, falls to zero. Subsequently, employees evacuate the premises once the flood water approaches then enters the property (vertical amber arrow). During the flood, a proportion of the SME's machines are damaged and raw materials ruined due to the depth the water reached. With some machines inoperable and raw materials damaged beyond use, the SMEs' ability to manufacture products once the flood water has receded is degraded. However, in the recovery period (vertical red arrow), due to a pre-existing mutual aid agreement with another SME, some agreed level of production at the other site is possible while recovery takes place at the flood affected SME's own premises. Simultaneously, those employees not re-located to the mutual aid partner's site work on recovery tasks including fixing machinery. Furthermore, eventually some employees become available for production at the SME's premises once it is able to be resumed. As shown in Figure 6, as machines become available, production capacity level increases.

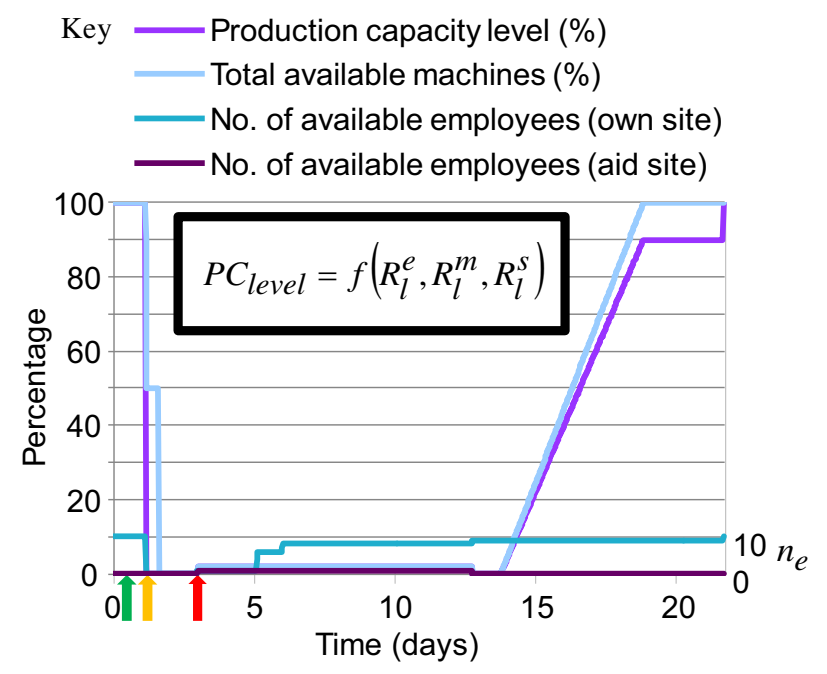

Figure 6: Sample output for an SME with mutual aid.

\subsection{Business continuity processes}

The aims of this strand of research are: (i) to gain an understanding of small businesses' response to flood events and their behaviours based on their experiences of flooding; (ii) to use the data gathered in (i) to inform the aforementioned ABM (see Section 3.1) and feed into economic impact analysis (see Section 3.3); (iii) 
complement organisational learning and related intervention tool initiatives (see Section 3.4).

\subsubsection{Case studies}

Six case studies comprising of 80 semi-structured interviews being undertaken as summarised in Table 1. In order to capture a range of SME experiences and behaviours, efforts have been made to identify case studies for investigation which: (i) represent different types of flood event; (ii) include small businesses from a variety of sectors; (iii) span different time periods.

\begin{tabular}{|c|c|c|c|}
\hline Case study & Year & $\begin{array}{c}\text { Number of } \\
\text { interviews }\end{array}$ & Flood type \\
\hline Sheffield & 2007 & 28 & Fluvial \\
\hline Tewkesbury & 2007 & 17 & $\begin{array}{c}\text { Pluvial/ } \\
\text { Fluvial }\end{array}$ \\
\hline Tyneside & 2013 & 6 & $\begin{array}{c}\text { Coastal / } \\
\text { Pluvial }\end{array}$ \\
\hline Warwickshire & 2007 & 17 & Fluvial \\
\hline The Wirral & 2013 & 6 & $\begin{array}{c}\text { Coastal / } \\
\text { Pluvial }\end{array}$ \\
\hline Romsey & 2014 & 6 & $\begin{array}{c}\text { Pluvial/ } \\
\text { Fluvial }\end{array}$ \\
\hline
\end{tabular}

Table 1. Case studies.

By identifying case studies in this way, it has been possible to capture both commonalities of experience and points of difference in terms of sector. A breakdown of the interviewed firms by sector is presented in Figure 7.

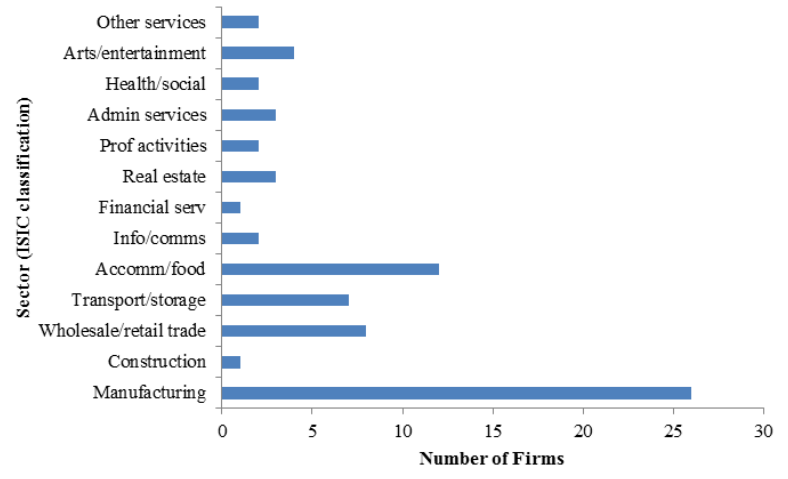

Figure 7: Sectoral breakdown of participant firms.

The approach taken to identify case studies also increases the potential to capture the impact of a changing organisational landscape in terms of flood response and recovery. For example, the Romsey case study provides data on response and recovery from businesses which were able to access central government funds for flood recovery; monies not available to businesses in other case studies. Also, the Sheffield case study has been more extensive than in other case studies to permit the investigation of novel public/private collaboration undertaken in the city in the wake of the 2007 flood. This includes the establishment of a Business
Improvement District (BID) to support flood resilience in the Lower Don Valley region of Sheffield.

In collaboration with the agent-based modelling and simulation research strand being carried out, additional data from participants has been gathered in the form of a brief survey to provide inputs for the ABM.

\subsubsection{Emerging findings}

A significant trend to emerge from the data gathered from semi-structured interviews is that while there is a range of guidance available to SMEs, from organisations such as the EA, few of them have formal planning and preparedness for flood risk. Reasons that businesses cite for having limited formal planning include a lack of knowledge about how to do this, even though they may be aware that guidance exists, and resource limitations in terms of time and cost. Even after the, often traumatic, experience of being flooded, many of the businesses interviewed have not implemented formal preparedness measures as recommended in guidance. Nonetheless, the businesses interviewed have all demonstrated, to some degree, resilience to a flood event. The data gathered suggests that this resilience has some foundation in the fundamental nature of the firms. That is, SMEs' day-today experience is often characterised by resource limitations as they do not have the scale of assets available as their larger counterparts. Thus, many businesses have developed capabilities or skills, over time, to make best use of the limited resources that they have for running their normal operations, e.g. flexibility, quick decision making and innovative approaches to problem solving. These are powerful tools in aiding resilience to a flood event.

More specifically, this capability or skill set is also strongly influenced across different levels such as the industry or sector and the firm's own past experience. In other words, key attributes such as innovation and flexibility can be highly path dependent. As an example, Figure 8 shows how one engineering/manufacturing SME fixed a high tension wire across a flooded street adjacent to their premises to enable stranded staff to evacuate and make their way to safety.

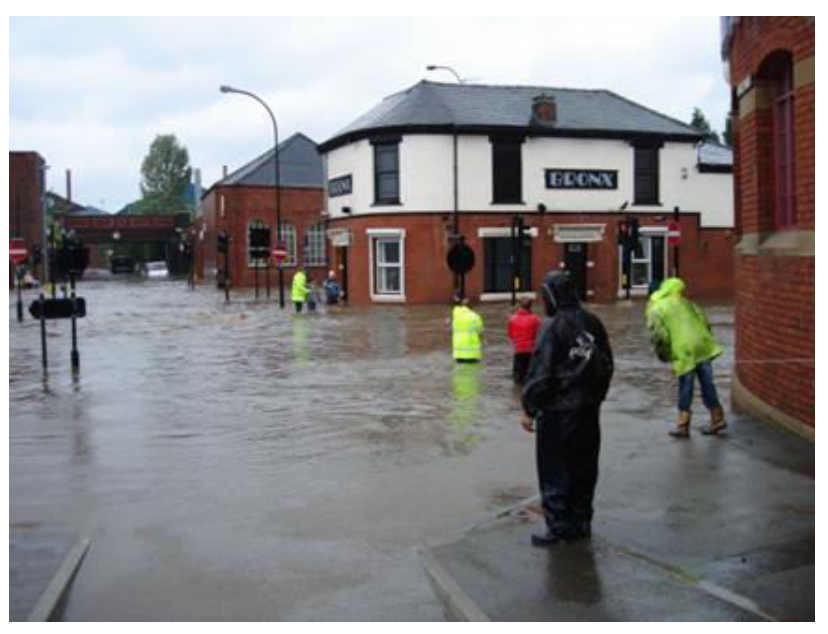

Figure 8: SME problem solving using existing resources. 
This example illustrates the way in which one small business brought their engineering approach to problem solving. It also shows them utilising their product in a novel way to solve the problem faced by some of their employees. The latter arguably reflects the firm's preexisting mind set of searching for new ways to deploy their products in order to unlock new markets for the business.

Insurance for flooding emerges as a major issue for SMEs at all stages of the flood cycle. Some businesses, which had not previously perceived themselves to be vulnerable to flooding, were not sure whether they had cover for losses arising from flooding until they spoke to their broker, or insurer, in the immediate aftermath of the event. The speed of claims settlement and how soon insurance payments are received is important as it affects the length of time that it takes for the firm to return to normal operations. A flood event typically impacts on a number of businesses in a locale at the same time. This can create pressure on brokers and insurers due to the volume of inquiries and claims within a short time frame, and some businesses felt that this impacted on their ability to recover as quickly as possible. Furthermore, a number of firms cited good relationships with insurance brokers as key in facilitating quick and fair claims settlements while others experienced delays arising from their inability to quickly provide evidence required by their insurers.

The emerging findings mentioned have important implications for the guidance that the SESAME project aims to produce to assist small business resilience to flooding. Firstly, given that pre-existing informal competences and networks can underpin effective resilience to a flood event, guidance should explicitly focus on helping business to make best use of that resource base in a way that they find accessible and easy to understand. Secondly, the data gathered indicates that there are certain practical measures in the response phase of a flood event that can have important ramifications for business recovery and financial sustainability in the longer-term. These issues shall be incorporated into the proposed guidance for small businesses.

\subsection{Economic impact analysis}

Analysing the economic and societal impacts of flooding is central to understanding and identifying costeffective adaptation and mitigation measures. Assessments of the impact of flooding have traditionally focused on the initial effect on people and assets, which are useful in understanding the immediate implications of damage, and in marshalling the pools of capital and supplies required for re-building post event. Since different economies and societies are coupled, any smallscale damage may be multiplied and cascaded throughout wider economic systems and social networks. This research strand sets out to gain an improved understanding of the economic impacts of floods events on SMEs, and the knock-on effects on the wider economy. Taken together, these can be described as the flood footprint, i.e. a measure of the total direct and indirect economic impacts caused by a flood event to the area that is flooded and to wider economic systems. To quantify the economic impact of flood events beyond the immediate local area affected, a flood footprint model can be constructed based on an adaptive input-output analysis. This strand of the SESAME project involves: (i) adapting the city scale Adaptive Regional Input-Output (ARIO) model to quantify the cost-benefit of adaptation measures for case study cities from a macroeconomic perspective; (ii) linking the city scale ARIO model with national input-output tables (for each case study city) to estimate the cost of local flooding to the national economy; (iii) using the ARIO model with results produced to study the flood impact on SMEs and the economic benefits of SMEs' preparedness and adaptation.

\subsubsection{City scale modelling}

As the ARIO model is based on Input Output (IO) tables, i.e. a compendium of national economic transactions among industrial sectors/agents, the 'regionalisation' of the data is needed. The process of scaling down the national tables is achieved using statistical techniques, which consider the region's economic structure and the regional share of the national economy. The data for the regionalisation of the IO tables comes from the Cambridge Econometrics' Multi-sectoral Dynamic Model, which provides regional disaggregation at 46 industrial sectors. Also, the ARIO model at monthly intervals has been developed, based on seasonal production data from the National Statistics Office.

\subsubsection{Case study}

Flood footprint modelling requires substantial amounts of data concerning the behaviour of producers and consumers. Given the SESAME project's study of the consequences of small businesses' responses to previous flood events, it offers unique access to information for the calibration of the flood footprint model. The information comprises the characterization of each interviewed business, the damage suffered in previous flood events, their response to allocate remaining resources to different client categories, labour reaction and adaptation. This information defines the behavioural parameters of the model for assessing the total economic impact of past flooding in the City of Sheffield.

The model estimates that after the 2007 flood it would have taken at least 17 months for Sheffield's economy to fully recover to the pre-disaster level. The flood footprint is $£ 511$ million, or $6.2 \%$ of the city's annual gross value added. As indicated in Figure 9, the direct and indirect footprint ratio is almost $1: 1$, i.e. $£ 286$ million and $£ 225$ million respectively. Also, the recovery path tends to be fast in the first months of the aftermath, whereas it slows down when the economy approaches its pre-disaster level.

The direct damage is concentrated in three sectors: electricity and gas; land transport, and warehousing and 
postal. The direct damage in these sectors accounts for over half of the total direct damage. Electricity and gas account for $£ 76$ million or $26 \%$ of total damage.

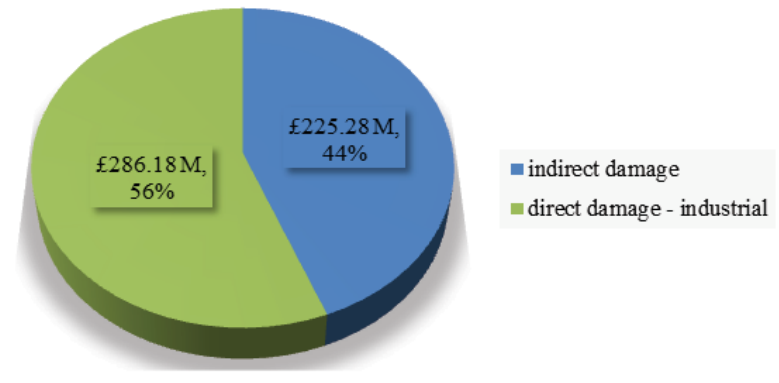

Figure 9: Direct/indirect damage for 2007 flood in Sheffield.

The remainder of the direct impact is more uniformly distributed among manufacturers (e.g. food, metals, chemicals and so on.) and some service sectors with a range of damage between $£ 4.5 \mathrm{~m}$ and $£ 16 \mathrm{~m}$. Among those sectors which were almost unaffected are professional and businesses services (e.g. legal and accounting, architectural and related, and other professional services). In the case of indirect damages, the most affected sectors were the businesses and support services with $£ 15$ million ( $7 \%$ of total indirect damage) and financial and insurance services with $£ 13$ million ( $6 \%$ of total indirect damage).

\subsection{Education of stakeholders}

This research strand has two aims: (1) to understand what influences whether and how small businesses make long-term adaptations to flood risk, which feeds into the development of the ABM; (ii) to develop a prototype elearning intervention tool for the promotion of business adaptation.

The academic literature suggests that the best way to change SME behaviours around flood risk is by embedding learning within relationships of trust and respect, and to take care to express all communications in a way that is familiar to businesses. The development of the intervention tool therefore needs to take place alongside the building of relationships and trust between SMEs, other businesses, and the organisations that work with them in resilience building. The tool is aimed at providing a virtual space in which SMEs can engage with flooding issues in terms that are familiar to them, so that they can recognise and address their own priorities for adaptation. The intervention tool is currently emerging from a process of co-production, i.e. iterative engagement between the research team, SMEs and national/regional stakeholders in business resilience.

This research strand has focused on developing and evaluating the co-production research processes in the creation of the prototype intervention tool to a stage where the tool can be piloted with specific business groups. This has involved working with businesses, and those organisations that support businesses with their resilience planning. The aim has been twofold: to explore the processes of 'co-production' and to research and develop the prototype tool. This phase of the work builds on several sources of information: a review of the literature on business learning; interviews with small businesses in Sheffield, Swindon, Tewkesbury and Tyneside; consultations with groups of stakeholders from a wide range of flood risk management/business resilience organisations and small businesses from Tewkesbury; engagement with businesses in Sheffield.

Co-production within the research process has involved the development of two separate groups. The Stakeholder Competency Group (SCG) comprises national and regional organisations that work with small businesses for increased resilience. These organisations include Business in the Community, the Federation of Small Businesses, local government (flood planners), the National Flood Forum, local resilience fora, and rural community councils (business advisers). This group has progressively increased its number of participants to 15 , and has provided opportunities for new and rich exchanges about business resilience between different organisations. The Business Research Partnership Group (BRPG) comprises businesses from Tewkesbury including representation from the retail sector, transport, catering, leisure, health and manufacturing. Importantly, at the outset, the group had not previously met together to discuss the major floods in 2007 and the group has been observed to undergo a transformative process as the coproduction process progressed.

In the development of the intervention tool, a coproduction process was used aimed at engaging a range of partners, and to integrate the contributions of representatives of all those with a stake in the SESAME project's aims and outcomes. To this end, all partners were engaged in developing the framework for intervention tool, i.e. the concept, structure, design, content, media and messages. A range of different media were used to deliver the content: text; digital stories (2-3 minute audio recordings played over personal images selected by the storyteller); interactive process flowcharts that explored business decision-making priorities and processes; and films of academic experts discussing technical issues with businesses. In addition, social media was employed in order to promote business-to-business communication.

The meetings with the SCG and BRPG formed an important stage in the development of the research process by providing information that informed the specification of the tool. The prototype tool is now being developed around the following themes: customer and supplier relationships; financial strategy before, during and after floods; understanding local flood risk and floodbuilding interactions; resistance/resilience strategies for reducing physical flood impacts; relationship building between the business and the 'community'; working differently as a business; building individual strength and developing coping strategies. As suggested in discussions with the SCG and BRPG, a variety of media are being incorporated into the tool to contribute to these themes including: written narratives that draw on stories of business adaptation captured in earlier interviews; digital narratives that capture the different adaptations of businesses after the 2007 floods (all co-produced with business people from Tewkesbury); interactive learning 
activities that focus on decision-making for property resilience, financial strategy and rethinking business processes; films of business people in discussion with scientists about local flood risk and property-level resilience. Taking a different approach to science communication from the traditional 'talking head podcast', these co-produced films have been created in the spirit of two-way Business and Science Exchanges that showcase the value of integrating local/lay knowledge and scientific knowledge.

The prototype tool has been reviewed with the SCG and BCPG at a combined workshop. This review had three aims: to assess current progress with the intervention tool and gain feedback for the final stages of the development; to celebrate local contributions to the tool; and to collect research data on the co-production process by reflecting on the experiences of being involved in the development of the tool.

\section{Conclusions and further work}

The SESAME project aims to understand and improve the way in which SMEs prepare and respond to flood events such that their resilience to flooding can be enhanced. To achieve this aim, four inter-related strands of research are being pursued, for which an overview of each has been presented in this paper. Based on an increased understanding of how these small businesses have responded to flooding in the past and how they may respond in the future, a computer modelling and simulation environment has been developed. This environment allows investigations to be carried out into the effectiveness of different types and combinations of SMEs' actions and behaviours in response to flood events. Also, an economic model has been developed capable of assessing the direct and indirect damage of a flood event anywhere in the UK. In addition, work has been undertaken to develop an e-learning intervention tool to be used by SMEs with the aim of promoting business adaptation thus strengthening resilience to future flooding.

In terms of future work, the modelling and simulation research strand will focus on performing benchmark simulations of SMEs for existing behaviours. Furthermore, experiments of simulations will be designed and performed in order to investigate the effects of different combinations of potential behaviours on the performance of SMEs. The business continuity processes strand will concentrate on the development of guidance for SMEs on flood resilience. For the research strand related to the education of stakeholders, the intervention tool will be trialled within the business communities in Tewkesbury and Gloucestershire. At the same time, additional research will explore the effectiveness of the narrative approach taken in the intervention tool. Finally, two dissemination events, involving SMEs and other stakeholders, will be held in Sheffield and Tewkesbury in May 2016.

\section{Acknowledgements}

The authors gratefully acknowledge the funding provided be the UK's EPSRC under grant EP/K012770/1.

\section{References}

1. http://www.environment-agency.gov.uk

2. Rhodes, C., Business statistics, Briefing paper 06152, House of Commons Library, December 2015.

3. McGuinness, M., Johnson, N., Responding to changing paradigms of risk: managing flood risk and enhancing organisational resilience, In Proc of the Association of Geographical Societies in Europe (EUGEO) 2013 Congress, 'Changing Geographies and Geographies of Change', Rome, Italy, 5-7 September 2013.

4. Reuter, C., Towards Efficient Security: Business Continuity Management in Small and Medium Enterprises, International Journal of Information Systems for Crisis Response and Management, 7(3), 69-79, 2015.

5. Coates, G., Hawe, G.I., McGuinness, M., Wright, N.G., Guan, D., Harries, T. and McEwen, L., A framework for organisational operational response and strategic decision making for long term flood preparedness in urban areas', In Proc of the 3rd International Conference on Disaster Management, A Coruña, Spain, 9-11 July 2013.

6. Elliott, D., Herbane, B. \& Swartz, E., Business Continuity Management, Routledge: London, 2001.

7. Herbane, B., The evolution of business continuity management: A historical review of practices and drivers, Business History, 52(6), pp. 978-1002, 2010.

8. Pitt, M., The Pitt Review: Lessons learned from the 2007 floods, Cabinet Office, 2008.

9. http://www.iso.org

10. Musgrave, B. \& Woodman, P., Weathering the Storm: The 2013 Business Continuity Management Survey, Chartered Management Institute: London, 2013.

11. Herbane, B., Small business research: Time for a crisis-based view, International Small Business Journal, 28(1), pp. 43-64, 2010.

12. http://www. ordnancesurvey. co. uk 